\title{
Fundamentos ético disciplinares de la responsabilidad social organizacional
}

\author{
Tello Castrillón, Carlos* \\ Rodríguez Córdoba, María del Pilar**
}

\section{Resumen}

El estudio de la Responsabilidad Social Empresarial ha tenido un sesgo marcado hacia los negocios. Así, la Responsabilidad Social Empresarial es instrumentalizada y se asemeja a una moda de gestión que, por tanto, luego puede ser descartable. Ante ello, el presente artículo asume el concepto más amplio de Responsabilidad Social Organizacional y se propone como objetivo plantear sus relaciones con lo moral. Esto es, reconocer la Responsabilidad Social como resultado ineludible de los fundamentos mismos de la conducta humana. Para tal fin, este escrito se divide en cuatro partes: el concepto de Responsabilidad Social Organizacional, sus fundamentos éticos, su relación con los valores y la ganancia privada y su dimensión pública. Al final, todos estos elementos permiten sostener la pertinencia moral de la Responsabilidad Social Organizacional y la necesidad de su promoción desde la acción estatal en lugar de estar sujeta a la plena voluntariedad privada. La gran conclusión del artículo es que la Responsabilidad Social Organizacional está siempre presente en la conducta humana y en los actos organizacionales y por tanto no es opcional. Al final, se plantean algunas sugerencias para futuras investigaciones respecto al tema.

Palabras clave: Responsabilidad social empresarial; responsabilidad social organizacional; ética organizacional; responsabilidad social; políticas públicas.

\section{Recibido: 03-06-16 Aceptado: 10-07-16}

* Profesor Asociado, Universidad Nacional de Colombia, Sede Palmira. E mail: catelloca@unal.edu.co

** Profesora Titular, Universidad Nacional de Colombia, Sede Manizales. E mail: mdrodriguez@unal.edu.co 


\title{
Ethical Disciplinary Foundations of Organizational Social Responsibility
}

\begin{abstract}
The study of Corporate Social Responsibility has been inclined to a business viewpoint that has transformed it into an instrument. Consequently, Corporate Social Responsibility seems to be a management style that might be disposable. In response, this article proposes a wider notion about Organizational Social Responsibility and its main objective is the statement of the relationship between Organizational Social Responsibility and morality. That means, to recognize Social Responsibility as an unavoidable part of human behavior foundations. To get so, this paper is fourfold: Organizational Social Responsibility concept, its ethical foundations, its relationship with values and private earnings and the necessity of an Organizational Social Responsibility promoted by the government in instead of being strictly voluntary developed. The main conclusion sets that Organizational Social Responsibility is always presented both in human behavior and organizational facts, therefore, it is not an optional choice. At the end of the work, suggestions for new research are proposed.
\end{abstract}

Keywords: Corporate social responsibility; organizational social responsibility; ethics; social responsibility; public policies.

\section{Introducción}

La Responsabilidad Social Organizacional (RSO) es inmanente a toda conducta individual y organizacional del ser humano y por tanto inmanente también a las organizaciones. Esto significa que la RSO es moral y no es optativa. Este documento constituye una reflexión sobre los fundamentos morales de la RSO y fue construido bajo una metodología hermenéutica a partir de una revisión bibliográfica. Con los resultados de la revisión inicial, se acudió al trabajo heurístico para ir incorporando relaciones entre la RSO y los conceptos éticos.

La Responsabilidad social empresarial (RSE) es un tema que surge referido al ámbito de los negocios como forma de reflexión para limitar moralmente las acciones pro ganancias de los ejecutivos. Esta discusión se remonta a los años 30 del siglo XX y se fortalece definitivamente a partir de los 60 (Carroll: 1979). Son clásicos del tema algunos autores como Carroll A. (1979), Drucker (1984), Freeman (1984), Elkington (1997) y, tomado como contra ejemplo, Friedman (1970). Estos y muchos otros autores más (Aguilera-Caracuel, Guerrero-Villegas, \& Morales-Raya, 2015; Dzbankova, 2011; Galbreath, 2009; Smith, 2007; Asociación Española de Contabilidad y Administración de Empresas, 2003; World Business Council for Sustainable Development, 2002; Comisión de las comunidades europeas, 2001) tratan la RSE desde lo empresarial sin que se encuentre la misma copiosidad en autores que asuman la reflexión ontológica respectiva.

La RSE por su carácter empresarial parece en muchos casos un conjunto de herramientas para las acciones que adelantan las empresas, es decir las organizaciones con ánimo de lucro. Tales herramientas aparentan ser inspiradas 
por principios de compromiso con el bienestar de todos los involucrados directa o indirectamente con la organización. Pero, más que ello, la RSE guarda dos fundamentos utilitaristas que no son tan evidentes para la sociedad: de una parte, sirve como instrumento para la promoción de la empresa en el mercado y, de otra parte, guarda un cierto aire de compensación a la sociedad por las ganancias pecuniarias obtenidas de ella.

Sin embargo, ha surgido una permanente ampliación del significado de la RSE desde el campo netamente empresarial hasta abarcar la totalidad de las organizaciones y así incluir aquellas que no tienen ánimo de lucro. Se supone que estas últimas (educativas, estatales, ONGs, iglesias entre otras) tienen como objeto una función que es social y no pecuniaria. Con esta ampliación, se pueden cuestionar dos hechos relativos a la RSE: a) que la Responsabilidad Social siempre tenga ánimo compensatorio y b) que todas las organizaciones tengan la posibilidad de incumplir con los valores socialmente deseables. Todo esto es una muestra de cómo la concepción de la RSE suscita diversas opiniones respecto a su naturale$z a$, su alcance y los indicadores que la evidencian. Por todo ello en vez de RSE es mejor utilizar el término Responsabilidad Social Organizacional (RSO) y así poderla referir a cualquier tipo de organización.

No se puede afirmar que, a priori, está garantizada la RSO de las organizaciones sin ánimo de lucro solamente en razón del cumplimiento de un objeto social redistributivo. Este último, al igual que el objetivo general de cualquier organización, da cuenta principalmente de su comportamiento frente a su usuario final sin que necesariamente de cuenta de lo que pasa con los otros Grupos de interés (GI). Entonces, para completar la visión de RSO, habría que averiguar si el tratamiento que una organización le brinda a todos sus $\mathrm{Gl}$ es justo. Tal justicia solo es posible a partir de decisiones moralmente correctas. Es por ello, que el presente artículo se propone plantear las relaciones de la RSO con lo moral de tal forma que se explore la naturaleza de esas decisiones.

\section{El concepto de responsabilidad social organizacional}

Las expresiones Responsabilidad Social Corporativa (RSC) y Responsabilidad Social Empresarial (RSE) son las expresiones más difundidas, en el mundo de habla hispana, del fenómeno de la Responsabilidad Social en cabeza de las organizaciones. Sin embargo, estas expresiones no alcanzan a cubrir el significado pleno de la RSO y por tanto resultan incompletas. La forma anglo para referirse a la RSE y la RSC es la expresión Corporate Social Responsibility (CSR) en la que corporate alude a lo corporativo. Estos dos últimos términos provienen de la raíz latina Corpus que significa ligado a un cuerpo. La expresión inmediata en Español para CSR sería Responsabilidad Social Corporativa. Sin embargo, parece ser que RSE es una expresión más mediática que RSC.

Esto se puede comprender sobre la base de la amplia difusión del significante empresa. Este término, que en Inglés corresponde a Business Firm o Firm, frecuentemente es usado para expresar el 
significado de Corporate, una asociación que ha sido discutida parcialmente por Enderle (2010). Por tanto, es usual que empresa reemplace a corporate en el tratamiento del concepto de RSC en Español. Sin embargo, empresa es cualquier tipo de organización con ánimo de lucro mientras que lo corporativo se refiere, en general, a un tipo particular de empresa donde resaltan dos grandes aspectos: a) una gran agrupación de capital financiero que adquiere una personalidad jurídica distinta a la de sus numerosos inversores y b) una estructura organizacional de unidades autónomas de negocio concéntricas alrededor de una junta corporativa (Williamson, 1989). Es evidente que las características de la corporación no cobijan a todas las empresas. Esto implica que empresa se refiera a un significado más amplio que el de corporación y que, por tanto, toda RSC esté incluida en la RSE. Es decir, la RSE solo eventualmente podría estar limitada a ser Responsabilidad Social estrictamente Corporativa.

De otra parte, el concepto de empresa no incluye a la variedad de organizaciones no empresariales. De esta forma, se excluyen tres importantes ramas de las organizaciones: las organizaciones sin ánimo de lucro (como las universidades, iglesias y clínicas entre otros), sus allegadas las organizaciones no gubernamentales ONG (que básicamente se definen por un objeto social encaminado a cumplir con funciones tradicionalmente asumidas por los estados, orientadas a la redistribución de la riqueza social) y las organizaciones estatales. Visto así, las empresas (que constan de corporaciones y no corporaciones) y los otros tipos de organizaciones se conjuntan para configurar la categoría Organizaciones.

Con todo lo anterior, queda establecido que corporación, empresa y organizaciones son términos que no se pueden equiparar. De hecho, el segundo rebasa al primero y el último rebasa a los otros dos. Al no ser equiparables, pensar en una Responsabilidad Social de tipo empresarial conlleva a confundir el tipo de relaciones que los otros tipos de organizaciones tienen con la sociedad. Por ejemplo, el enfoque en el desarrollo sostenible propio de la Responsabilidad Social de las Universidades (Urdaneta y otros, 2016) quedaría invisibilizado bajo un manto de rentabilidad pecuniaria. Los razonamientos anteriores finalmente llevan a descartar el uso de las expresiones RSC o RSE y a poner en su lugar la expresión RSO. Esta será la utilizada en adelante, incluso en las referencias tomadas de otras fuentes.

Para visibilizar el significado internacional del concepto de RSO se hizo su búsqueda en inglés, para el período entre enero de 1990 y marzo de 2011, en las base de datos EBSCO y Omnifile full text mega. En la primera base de datos aparecieron 941 títulos para Corporate Social Responsibility (CSR), y solo dos artículos referidos a Organizational Social Responsibility (OSR) (Popa, 2010; Markel \& Barclay, 2009). En la segunda base de datos se encontraron 1379 títulos para CSR y 1 título para OSR (Atkinson, 2010). En los textos sobre OSR, esta aparecía prácticamente como sinónimo de CSR.

La forma ortográfica para el significado de Organización utilizada en el Reino Unido y en los países de influencia Bri- 
tánica es Organisation y de ella se deriva Organisational. No se halló ningún artículo con esta forma, hecho que no sorprende toda vez que la forma norteamericana Organization es más internacional. Todas esas ambigüedades y traslapes son un ejemplo de las imprecisiones en los términos de la disciplina de estudio de la RSO de las cuales se quejó Enderle (2010).

Las imprecisiones de la RSO también vienen con la ausencia de una forma legítimamente dominante de RSO. EI concepto de RSO oscila dentro de un rango formado, de un lado, por los criterios universales del comportamiento socialmente responsable y, de otro lado, la normatización puntual de ese comportamiento en cada contexto. Esto es, un movimiento entre el fundamento ético y la aplicación moral. De estos dos extremos, la oscilación de la RSO tiende más hacia su característica normativa (Enderle, 2010; Melé, 2007). Sobre la indefinición, Enderle (2010) lamentaba la falta de precisión tanto en lo que se quiere decir con Responsabilidad como en el radio de acción de lo Social. Esto fue resultado de su contrastación del concepto de Responsabilidad Social Organizacional con el de Ética en los negocios. Al final, el autor visualizó una RSO más cercana a los estudios sociales ${ }^{1}$ mientras que situó la Ética en los negocios más próxima a las humanidades y al ánimo de lucro.

Una de las definiciones más difundidas de RSO es la instaurada por la Comisión Europea que insiste en la iniciativa voluntaria y no obligatoria de la RSO (Ungericht y Hirt, 2010). De otra parte, el World Business Council for Sustainable Development (WBCSD) es otra entidad de gran alcance internacional que define la RSO, con mayor precisión que la Comisión Europea, en procura de fomentar la relación de "la gente de los negocios en cooperación con los gobiernos y la sociedad civil" (World Business Council for Sustainable Development: 2002:1).

Jenkins (2009) partió de la prescripción del WBSCD como ejemplo para resaltar algunas características comunes entre distintas definiciones de la RSO: es un concepto que varía entre autores y organizaciones; por lo general es relativo al desarrollo sostenible expresado en lo social, lo ambiental y lo económico; involucra a muchos $\mathrm{GI}$ sin limitarse al interés de los accionistas; es voluntario y trasciende el cumplimiento llano de las reglas. En el aporte de Jenkins se destaca que la RSO debe ser vista como una actividad "pre ganancias". Por lo tanto, las "actividades filantrópicas" o las "donaciones caritativas" (Jenkins, 2009, pág. 69), en tanto actos "post ganancia", no son verdaderamente actos de RSO. Así, la incorporación de la RSO debe afectar la ganancia de la organización y no debe quedar relegada a ser un acto opcional.

En las citadas definiciones de RSO, son nítidas la voluntariedad del acto de RSO y su cercanía a lo normativo moral. Dentro de este marco normativo, la RSO gravita entre la moralidad de lo mercantil y la moralidad de lo sostenible. 
Una díada de la que surgen dos grandes tendencias en el estudio de la RSO que aquí se llamarán tendencia instrumentaly tendencia sostenible. En estas dos tendencias e inscriben las cuatro escuelas de RSO a las que Melé (2007) se refirió. Dado que no es precisa la madurez de los núcleos teóricos de las escuelas señaladas por Melé, este escrito se refiere a ellas como corrientes.

La primera tendencia concibe la RSO como otro instrumento mercantil sobre el cual se apoya la nueva competitividad. Esto implica que en ella no se abandona la primacía del lucro para los accionistas y por tanto el afán de eficiencia financiera. La segunda tendencia visualiza la RSO como un acto de compromiso con la sostenibilidad integral de la sociedad.

En la primera tendencia se encuentran dos grandes corrientes. La primera y más famosa de ellas es la corriente del Valor Para el Accionista (VPA). En inglés es conocida como la Shareholders theory que, en contraste con la Stakeholders theory, solo se concentra en los accionistas (Shareholders) en desmedro de los otros GI. Los autores más famosos de esta corriente (Friedman, 1970; Drucker, 1984) argumentaron que la única forma de RSO válida consiste en la generación de valor para los accionistas toda vez que para ello la organización tiene que actuar con criterios de eficiencia. Estos últimos implican el cumplimiento a la sociedad tanto en el buen uso de los recursos como en el incremento en el bienestar de sus individuos.
Una segunda corriente de esta tendencia instrumental ve la RSO como una forma de mejoría de las transacciones de la organización debido a su buena reputación. En esta corriente, llamada la corriente de actuación social de la empresa (ASE) (Carroll, 1979), los actos sociales de la organización están encauzados hacia el aumento de la ganancia económica. Aquí se aboga por el logro de resultados organizacionales evidentes utilizando también como medio la incorporación del respeto por los valores morales demandados por la sociedad. En el mismo sentido, Koslowski $(2007)^{2}$ vio en la RSO una buena forma de corregir fallas de coordinación en el mercado en razón de que agiliza las transacciones de las organizaciones. Entonces, la RSO es ejecutada por la organización en la medida que sus decisores consideren que los beneficios de su actuación superan los costos de su implementación. Cuando esto cesa, no hay fuertes motivos para que la organización siga siendo socialmente responsable.

De otra parte, las corrientes de la tendencia sostenible son dos: la corriente de los GI y la corriente de la Ciudadanía empresarial. Nuevamente, como en la presentación de la tendencia instrumental, aparece en primer lugar la más famosa y conocida de las dos. Se trata de la corriente de los GI llamada literalmente teoría por su autor original (Freeman, 1984). En ella, se acude al ya extendido concepto de los Stakeholders o GI. Aquí se concibe a la organización como parte integral de la sociedad y como nodo de 
relaciones sociales de los distintos grupos interesados en el desempeño organizacional a los cuales la organización debe retribuir equitativamente. La retribución equitativa, o sea conforme a la contribución que cada quien le aporta a la organización, es la base del equilibrio organizacional $^{3}$ (Simon, 1997). Con esta idea de RSO se está elevando a primer plano el valor de la Justicia en un escenario donde la organización, en tanto componente de la sociedad, está obligada de forma ineludible a ser socialmente responsable.

La cuarta y última muestra de este orden corresponde a la corriente de la ciudadanía empresarial (CE). Esta sitúa la organización en la misma posición de una persona en la sociedad. Lo que implica que ella posee derechos y obligaciones sociales y es un actor social de quien se espera un buen comportamiento. Bajo esta propuesta, normativa en esencia, la organización debe voluntariamente asumir una conducta de "buena ciudadana" (Melé, 2007: 62). Desde la "declaración firmada por 34 directores ejecutivos del mundo dentro del World Economic Forum de 2002" (Melé, 2007, pág. 62) surgió esta idea que implica que la RSO se logra con el cumplimiento del mandato de buena ciudadana no solo en su ámbito local sino también a nivel global.

Actualmente, se trabaja la RSO con énfasis en una perspectiva de gestión intra organizacional ${ }^{4}$. Se trata de su instrumentalización en sistemas de gestión de calidad, de gestión ambiental y de salud y seguridad ocupacional por medio de las ISO 9000, ISO 14000 y OHSAS 18000 , respectivamente. Por su parte para la RSO como un todo se creó la ISO 26000. Todo este conjunto de normas y guías reafirma un doble rol de la organización frente a su RSO: a) la organización por sí misma es capaz de controlar en alto grado las variables que la llevan a posicionarse en el entorno $y, b$ ) por tratarse de normas y guías, la RSO sigue siendo voluntaria.

\section{Responsabilidad social organizacional: fundamentos éticos}

La Ética es una disciplina de estudio de las humanidades encuadrada en la Filosofía. "se entiende como la reflexión filosófica de la moral y, en consecuencia, es una parte de la Filosofía como lo son la Metafísica, la Epistemología o la Estética" (Rodríguez et al. 2016, pág. 91). La Ética se concentra en la ontología de 10 moral buscando los elementos comunes a las distintas definiciones de lo bueno y lo malo. Es decir, la Ética responde al consenso sobre lo moral que, en tanto consenso y hecho social, es una propiedad humana que puede consignarse bajo la forma de Instituciones, tal como las explicara Searle (1997).

3 Sobre el tema del equilibrio véase también a Tello Castrillón, capítulo seis (2009).

4 Cegarra Navarro y Rodríguez Carrasco (2004), por ejemplo, hablaron de las influencias de la organización sobre el entorno. Ellos utilizaron una perspectiva intra organizacional de recursos y capacidades relativos a la creación y gestión social de conocimiento colectivo con el fin de po- 
Las grandes tendencias de la Ética en la historia, fueron expuestas por Yazdani y Murad (2014). Para los autores, existen tres grandes marcos generales de referencia sobre esta disciplina: dos tradicionalmente estudiados: "a) uno basado en los deberes (el marco deontólogico), b) otro basado en metas y objetivos (la visión teleológica); desde hace unas pocas décadas $\mathrm{c}$ ) las perspectivas axiológicas han sido adicionadas a este

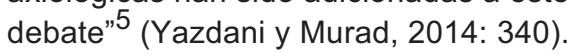
Esto último es especialmente relevante, porque ha trasladado la discusión frente al tema desde los objetivos y/o los deberes hacia los valores, especialmente morales, de las personas y las organizaciones. Los marcos (a) y (b) se diferencian por su posición frente a la determinación apriorística de los valores morales (Singer, 1989). La determinación ex ante se cumple para los afiliados al marco deontológico, cuyo mejor exponente es Kant. Por el contrario, el marco teleológico asume que esos valores morales se determinan a posteriori en las declaraciones fácticas.

Los marcos (a), (b) y (c) se convierten en cinco marcos teóricos específicos de lo ético: i) Ética del mandato divino, basada en decretos divinos, escrituras y dogmas (en esta se encuadran Platón, San Agustín, Mahoma); ii) Consecuencialismo, que promueve las decisiones que suponen las consecuencias más favorables y deseables, sea cual sea su na- turaleza (Maquiavelo, Bentham, Mill, Nietzsche); iii) Ética deontológica, donde los actos nacen en los deberes categóricos y no están determinados por los fines a conseguir (Confucio, Kant, Ross, Rawls); iv) Ética de lo virtuoso o de la excelencia, relativa a los actos encaminados al logro de las virtudes, la caridad, la justicia y la compasión, como fines de la actividad humana (Aristóteles, Hobbes, Macintyre) y v) Relativismo, subjetivismo o relativismo moral, que defiende la posición dominante de los valores culturales y sociales como determinantes morales (Yazdani y Murad, 2014). Puede inferirse, que i y iii son cercanos en cuanto priorizan el razonamiento basado en el origen de los actos humanos. En contraste, ii y iv se asemejan en la prioridad que le dan a la consecuencia del acto, con marcada diferencia en la naturaleza de esa consecuencia. Adicionalmente, puede decirse que $v$ mezcla un poco de todos.

Lo ético aborda la reflexión ontológica de orden superior que luego la norma moral expresa en forma de comportamiento última, visible, tangible y manifiesta al alcance de la mano del individuo en cada situación de su vida diaria (Sánchez Vásquez, 1969). Mientras que lo ético es un asunto "teórico moral (es)" (Sánchez Vásquez, 1969: 17), lo moral es un asunto de contenido "práctico moral" (Sánchez Vásquez, 1969: 17). A su vez, lo moral es el esquema de valores morales del individuo (Cortina, 2000) y determina sus

sicionar la organización en la sociedad. De acuerdo al ordenamiento propuesto en este texto, este estudio puede inscribirse en la corriente ASE. 
ideas, principios e imperativos (Sánchez Vásquez, 1969).

La finalidad práctica de 10 moral consiste en servir de medio para que los seres humanos establezcan acuerdos mínimos de convivencia en aras de que se ejecuten actos que aporten a la sostenibilidad social. "... [Lo] moral cumple una función social muy precisa. Contribuir a que los actos de los individuos o de un grupo social se desarrollen en forma favorable para toda la sociedad o para un sector de ella" (Sánchez Vásquez, 1969: 61).

Lo moral asume la forma concreta de la moral de cada grupo humano, adoptada por cada individuo, en un determinado tiempo y espacio. La moral existe como relación entre el sujeto y los demás humanos (Cortina, 2000: 45) dando explicación de los "fines últimos" (Cortina, 2000: 49) de toda actividad humana, incluida la Ciencia. Aunque es similar a las leyes, porque se expresa en la forma de restricciones -las normas morales-, la moral es aceptada por el individuo sin necesidad de la presión de una autoridad. Se trata de una aceptación racional y dirigida desde la conciencia (Singer, 1989). Dada su cercanía, y en aras de agilizar el discurso del presente texto, lo moral y la moral serán tratados conjuntamente dentro del término lo moral.

Lo moral está vinculado a la concepción de los valores. Para Sánchez Vásquez los valores no existen por fuera de los objetos ni por fuera de los seres humanos y aunque trascienden el ámbito individual no trascienden el ámbito social. "los valores (...) únicamente se dan en un mundo social. Es decir por y para el hombre” (Sánchez Vásquez, 1969: 123), “... solo lo que tiene una significación huma- na puede ser valorado moralmente" (Sánchez Vásquez, 1969: 125). Debe evidenciarse que la valoración de algo es obligatoriamente un acto consciente que implica responsabilidad.

Los valores toman forma bajo la figura de los bienes. Estos valores son de naturaleza ontológica, lo que les confiere su permanencia, mientras que los bienes en lo que recaen van cambiando praxeológicamente. El concepto de Bien proviene originalmente de la Ética y es una de las piedras angulares y evidentes de su relación con la Economía y lo empresarial. Originalmente, el Bien es la representación de lo bueno y con el paso del tiempo su concepto adquirió la forma adicional de bien económico (Koslowski, 2008: 33). Este útlimo, bajo una economía de mercado, se convirtió en Mercancía. El Bien, como categoría social, tiene tres dimensiones: "el bien moral, lo efectivo y lo eficiente" (Koslowski, 2008: 35).

Mientras la primera corresponde a la categoría ética, las otras dos corresponden a lo tecnológico y a lo económico. Sin el cumplimiento de una de las tres dimensiones no se puede hablar de que algo es integralmente bueno (Koslowski, 2007). Pero, en razón de que la moral es el dominio de donde deviene el concepto de bien, el bien moral tiene un rango superior y subsume las dimensiones de lo efectivo y de lo eficiente. Por ello, toda acción basada en los valores morales tendrá como resultado la generación de un bien.

Entre los distintos tipos de valores se encuentran los valores morales, la base de lo moral. Un ordenamiento de los valores permite visualizar la importancia del valor moral dentro del pleno la con- 
ducta humana. Para ello, es útil la escala de J. de Finance (citado por Sanabria, 2005), quien clasificó los valores en un orden jerárquico ascendente de la siguiente manera: 1. "Valores infrahumanos" (de sensibilidad y vitales o biológicos) que no distinguen al hombre del animal y cuya exacerbación es el Hedonismo y su hipertrofia es el Puritanismo 2. "Valores humanos inframorales" que aún no perfeccionan a la persona pero que ya no son compartidos con los animales.

En esta categoría se incluyen los "valores económicos" y los "valores eudemónicos" (búsqueda de la felicidad como fin último); los "valores noéticos" alusivos al conocimiento; los "valores estéticos"; los "valores sociales" dirigidos al posicionamiento social y los "valores síquicos"; "3. Valores morales". Referidos a la libertad. Esta es la verdadera realización de la persona y es muy cercana a " 4 . Valores religiosos", relativos a lo supremo (Sanabria, 2005: 75).

De acuerdo a esta escala, los valores morales son superiores a los valores económicos al tiempo que están muy ligados a los valores religiosos. Aristóteles ya había clasificado las virtudes como parte de lo supremo mientras que había relegado lo económico a lo inferior (Yazdani y Murad, 2014). De otra parte, la naturaleza normativa de los valores morales tiene distintas interpretaciones según se trate de lo sociológico o de lo filosófico.

Para lo primero, esta naturaleza surge en las declaraciones de los actos y para lo segundo, se basa en los juicios de valor. Así, se configuran las diadas de causalidad "acto/valor" y "es/deber ser". Ambas diadas son equivalentes y en ambas se ubican primero la declaración fác- tica -acto, es-y luego la declaración lógica -valor, deber ser-. Las díadas se preocupan por saber si el origen del valor está en los actos, el supuesto que asume la Sociología, o es independiente de estos (Singer, 1989: 146), la consideración reflexiva que la Filosofía también incluye.

Los valores morales son un también un elemento argumentativo central en el concepto de la Responsabilidad. Lo moral prescribe, con argumentos compartidos por un grupo, los actos "libres, y por tanto responsables e imputables" (Cortina, 2000: 45) de la conducta humana. "El problema de la esencia del acto moral remite a otro problema importantísimo: el de la Responsabilidad" (Sánchez Vásquez, 1969: 18). La cadena causal de la conducta responsable, inicia en la autoconciencia del sujeto que luego faculta para el ejercicio de la libertad del acto individual.

De esta forma, es evidente que la escogencia de un curso de acción, conforme a las preferencias que ordenan lo que el individuo ha aprendido a considerar como valioso, hace que todo acto sea moral. El acto consciente del individuo lleva a la más humana de todas las condiciones: die Stellungnahme o la fijación de posición (Koslowski, 2008: 34) para la toma de decisiones. De ahí, finalmente se configura "la responsabilidad personal en el comportamiento moral" (Sánchez Vásquez, 1969: 63).

\section{Responsabilidad social organizacional, valores y ganancia privada}

El economicismo lleva más de dos siglos actuando de prisma teleológico de 
las acciones individuales en las economías de mercado. Su base moral ha sido el cientificismo ${ }^{6}$ criticado por Cortina (2000). El economicismo es la versión actual de la influencia de la crematística, un fenómeno indeseable que ya había sido criticado por Aristóteles. En general, el esquema valorativo del Capitalismo degeneró lo económico y asumió el economicismo como visión hegemónica.

De esta manera, se ha resaltado una visión individualista; la producción excedente a ultranza; el tener como forma de realización personal y la ganancia no compartida con los otros, como fin terminal de las organizaciones y las personas. Estos propósitos han logrado mantenerse a lo largo del tiempo gracias a la promoción que se hace desde las escuelas de negocios, las asociaciones gremiales y las consecuentes prácticas organizacionales del medio. Esta lógica, orientada por los valores propios de una ética consecuencialista, descuida el entramado social que es necesario para el logro de la ganancia. De hecho, entiende al entramado social simplemente como una variable exógena al mercado.

Sin embargo, los defensores de la ganancia suponen que ella es moralmente positiva. De una parte, en la mayoría de los casos, se asume la ganancia como un indicador proxy de lo efectivo y lo eficiente. En consecuencia, la ganancia da cuenta del mejor aprovechamiento de los recursos socialmente disponibles. De otra parte, la ganancia hace parte de las bases que motivan al hombre de empre- sa a seguir actuando y, por lo tanto, no tiene por qué ser necesariamente anti moral (Koslowski, 2008). Sin embargo, sí es anti moral pensar que la ganancia es el fin terminal e incuestionable del ejercicio organizacional y personal. Esto quiere decir que la ganancia no puede ser elevada a la categoría ontológica. Basta recordar que la ganancia se ubica, en la escala de de Finance, entre los valores humanos inframorales, una categoría inferior a la de los valores morales.

En contraste, y de acuerdo a la escala de Finance (Sanabria, 2005), la RSO está ubicada en las categorías superiores correspondientes a los valores morales y a los valores religiosos. En el primer caso, porque regula las libertades individuales de los actores sociales, incluyendo las organizaciones, en aras de que la acción de un actor no entorpezca las posibilidades de que los otros realicen las suyas. En el caso de los valores religiosos, porque la responsabilidad mutua entre los actores sociales es un concepto transcendental y supremo, relativo a la dignidad y autonomía humanas (Kant, 2012), solamente asimilable mediante la reflexión ontológica profunda. El reconocimiento de la RSO dentro de estas dos categorías de valores, hace parte de la solución de la divergencia entre los imperativos éticos y los imperativos económicos.

Se trata de una divergencia que nace, a su vez, de la diferencia normativa entre Ética y Economía. Mientras la primera dirige la acción humana hacia lo mejor, concepto etéreo e impreciso, en 
contraste, la segunda cuenta con un objeto de la alta puntualidad: la eficiencia, que se empieza a gestar desde los procesos tecnológicos enfocados en lo efectivo (Koslowski, 2008: 32). Sin embargo, la divergencia citada se alivia, aseguró Koslowski, al remarcar que las normativas de eficiencia y efectividad siempre deben estar subordinadas a la normativa de 10 mejor. Esto es cierto, aun cuando lo mejor no siempre pueda ser alcanzado ante la inevitable presencia de restricciones -sociales, económicas y cognitivas- en la acción humana ${ }^{7}$.

Si se toma lo moral de forma funcional al servicio de la ganancia, se lo está refiriendo a algo ajeno a su verdadero propósito. Peor aún, lo moral solo sería considerado importante mientras satisfaga una misión rentable, pero una vez termine esta capacidad, lo moral podría ser reemplazado por otro instrumento que consiga sus mismos resultados, como si lo moral fuera prescindible. Trabajado así, lo moral no es persuasivo y fácilmente puede ser abandonado (Koslowski, 2008: 38). Sin embargo, el respeto por el verdadero propósito de lo moral no obsta para que algunas veces las personas y 10 moral puedan ser temporalmente considerados como medios para un logro económico.

La divergencia parcial entre los imperativos económicos y éticos también se refleja en la RSO. De una parte, como ya se ha dicho, la RSO es sometida a los valores del sistema capitalista y puesta al servicio de la ganancia. De otra parte, la
RSO es resultante de los valores que expresan los deseos de bienestar y prolongación de la sociedad. En este sentido, los juicios morales concretados en la RSO categorizan los actos organizacionales según su bondad o perversidad con el bienestar y prolongación de la sociedad, a través de patrones como lo amigable con el medio ambiente, producción limpia, socialmente responsable, buenas prácticas de manufactura, entre otros. Pero, si cada organización -o actor social en general- asume una forma particular de lo moral que le sirva para concentrarse en su ganancia particular, atenta contra la estabilidad de todas las demás organizaciones y la de la sociedad en general. Por eso, es necesaria una moral común a todas las empresas (Koslowski, 2008) surgida desde los valores derivados de los imperativos éticos. Esto redundaría en una RSO uniforme y comprometida con la dignidad humana.

Las incongruencias y coincidencias entre los juicios de valor de la Ética y la Economía pueden ser desarrolladas por medio del objeto de estudio de la Ética (Koslowski, 2008, págs. 34-35). Estas relaciones remiten a las discusiones sobre el acto/valor y el es/deber ser de los actos humanos. El es tradicionalmente connota en la sociedad capitalista una esencia instrumentalista y afanosa por la eficiencia que supone la adecuación sistemática de los medios en dirección a los fines pecuniarios. En ese orden de ideas, la explicación del comportamiento moral se basa, tal como se hace en Administra- 
ción, en "los factores biológicos, psicológicos o sociológicos que componen la razón estratégica" (Cortina, 2000: 22). Aquí se puede afirmar que el concepto de razón estratégica que cita Cortina se corresponde con la Racionalidad formal (o simplemente racionalidad) consuetudinariamente trabajada en la Economía neoclásica, las prácticas ingenieriles, el modelo racional de toma de decisiones y la Burocracia weberiana (Hatch, 1999). Al final, el es social del capitalismo tiende a eliminar la presencia del deber ser social.

La falta de visualización del deber ser social implica el descontrol individual y social. De acuerdo a Platón (Koslowski, 2008), lo ético actúa en aquellos puntos donde el control social no puede cumplir. llustrativo de esta situación es la forma en que la moral, en tanto común a un grupo social, aparece como un elemento diario re socializador de las contradicciones estructurales de clase en la Economía. Existe, por tanto, la necesidad de cultivar una formación moral proclive al respeto de los otros individuos - presentes y futuros- ya que el panóptico social siempre deja esferas sociales sin control, en las que solo la autonomía individual, bajo normas auto impuestas, puede influir. Así, el control social que implica lo moral, es un rasgo esencialmente humano, es difícil concebir otra especie que reflexione sobre su comportamiento, al servicio de su supervivencia como especie.

En consonancia, la RSO, en tanto manifestación de lo moral, también apun- ta a la supervivencia de la especie humana. Cuando los sujetos organizacionales asumen las consecuencias de sus actos conscientemente decididos, se configura una actuación responsable. Adicionalmente, toda actuación moral es social e inmanente a todo individuo. Por eso, la Responsabilidad Social es inmanente a cualquier individuo consciente en relación a los demás y de ahí, se encuentra vinculada a la supervivencia de la especie. Cuando se reconoce la organización como actor social ${ }^{8}$, por ejemplo como es tomada por la corriente de la ciudadanía empresarial, la RSO pasa a ser una de sus características inmanentes y por tanto, se enrumba hacia la supervivencia de la especie humana. La relación de la RSO con la supervivencia no tendría por qué reñir con los objetivos económicos. La Economía también aporta a la supervivencia de la especie humana en cuanto lidia con la repartición de la riqueza material.

Koslowski (2008: 32) afirmó que el interés por la supervivencia hace de la Ética y la Economía disciplinas cercanas que, sin embargo, en algunos aspectos entran en conflicto, comportándose como "hermanos adversos" (2008: 32). La cercanía entre estas dos disciplinas proviene de tres grandes relaciones: a) ambas trabajan con "teorías sobre el comportamiento humano y la toma de decisiones" (Koslowski, 2008: 32). b) Ya que las dos involucran "las dimensiones prospectiva y retrospectiva" (Koslowski, 2008: 32) 
ambas acuden a la especulación. Para el caso de la Ética la especulación es mucho más sentida toda vez que se concentra en reflexiones de nivel supremo y c) La Ética y la Economía articulan gran parte de sus discursos alrededor del concepto de bien.

Sin embargo, el sistema económico fue atrapado por el cientificismo y devino en una dependencia de la racionalidad formal, así llamada por Weber (Hatch, 1999), donde prima lo racional instrumental, en tanto medible, programable y evidenciable empíricamente. Desde esa óptica, la objetividad, supuestamente plena, de lo racional instrumental es la condición que configura la universalidad de las categorías morales. A partir de ello, lo racional formal permite las relaciones con los demás mientras que lo irracional queda relegado para el ámbito unipersonal (Cortina, 2000: 49). En este orden de ideas, lo moral solo tendría validez a nivel privado. De esta forma, el cientificismo bloquea lo moral, lo relega a lo privado y sentencia que para lo público solo puede operar la racionalidad instrumental.

La separación entre lo moral y lo racional, encierra el deber seren la decisión $\mathrm{y}$ el es en el conocimiento. Con esto, se blindaría la Ética de la Ciencia y viceversa (Cortina, 2000). Sin embargo, desde una reflexión adicional, esta separación es imposible. Por ejemplo, la perfección racional instrumental en la ejecución de un acto no habilita su pertinencia. Es la intencionalidad con la que se lleva a cabo, la que conduce a que valga la pena hacerlo bien, la misma intencionalidad que Weber propusiera como racionalidad sustantiva (Hatch, 1999). De esta forma, no puede estimularse que un acto malo sea ejecutado a la perfección (Koslowski, 2008: 34). Así, un verdadero sentido de RSO se encuadraría en esta discusión sobre el es/deber ser también desde lo fáctico y desde lo lógico. En el primer caso, porque señala la amenaza que representa el acto empresarial para la sostenibilidad de la sociedad. Desde lo lógico, porque esa RSO incorpora los valores morales de lo Bueno y lo Justo que configuran dicha sostenibilidad.

Aun si se aceptara que lo moral pertenece al ámbito privado unipersonal, su carácter relacional no desaparecería. Lo unipersonal o privado solo tiene sentido en presencia de lo público. Singer (1989) argumentó que la identidad propia solo se construye a partir del reconocimiento de los demás y que por eso, incluso, el individuo solitario tiene una base social para su moral. Entonces, lo moral es siempre relacional y referido a los actos del individuo en cuanto miembro de una sociedad a la que, obligatoriamente, afecta (Sánchez Vásquez, 1969). De ahí que todo comportamiento moral sea un holograma de la Responsabilidad Social y que todo comportamiento económico también sea moral. Por ello, se puede decir que la RSO es un imperativo moral organizacional que es irreducible y está vinculado con la dignidad y la existencia humanas.

\section{La dimensión pública de la responsabilidad social organizacional}

La dimensión pública está inmediatamente conectada con los GI, cuya coordinación de intereses se hace mediante negociaciones permanentes en dinámi- 
cas políticas. El GI más destacado es el Estado, quien ejerce su autoridad política sobre todo el sistema social de forma tal que interviene en la coordinación de los intereses de los demás GI. La intervención política estatal tiene especial efecto en la actividad organizacional, lo que llevó a que Bozeman (1987) afirmara que cualquier organización es pública en algún grado. Las presiones de los $\mathrm{Gl}$, crean una agenda pública para la expedición de leyes que formalizan la defensa de sus intereses (Méndez Picazo, 2005: 145). Estos intereses son un elemento central en la configuración de la RSO.

La agenda pública puede crear una regulación estatal que se complemente con la regulación social. Esto con el fin de dar solución al conflicto moral que subyace en la coordinación de intereses de los GI. Tal solución debería estar basada en dos aspectos: el primero, alusivo a la correcta jerarquización de los bienes morales, por encima de lo efectivo y de lo eficiente. El segundo aspecto se concentraría en la dimensión pública de la RSO, lo que incluye discutir la aceptación de una RSO estrictamente voluntaria o el planteamiento de una RSO que sea impuesta o promovida desde el Estado (Ungericht \& Hirt, 2010).

Para ello el Estado puede acudir a su monopolio del derecho y a la promoción de lo moral. El derecho esencialmente tiene un carácter prohibitivo y coercitivo que no alcanza a regular todas las actividades del individuo. En contraste, 10 moral rige todas las actividades del individuo y tiene un carácter más propositivo y activador de conductas (Sánchez Vásquez, 1969). Por ello, las leyes y lo moral son complementarios en la regulación de las relaciones sociales (Sánchez Vásquez, 1969: 60). Al final, la acción legal del Estado resulta ser más inmediata y apta para las medidas de choque contra conductas atentatorias de la RSO mientras que la acción de lo moral resulta ser más mediata y apta para su sostenibilidad. Lo último guarda correspondencia con el nivel superior de la posición deontológica en la cual los valores morales y los valores religiosos están por encima de todos los demás.

Lo moral y la responsabilidad, en tanto relacionales, son relativos al entorno y pueden ampliarse hacia el habitar mismo en sociedad. Así, emerge una RSO que obligatoriamente remite la organización al respeto por el entorno. Se entiende un entorno que no es ajeno ni extracorpóreo sino que es parte integral del ser humano. De esta forma, el hombre es tomado como la base del sistema social $y$, a su vez, el sistema social se entiende como el espacio donde tiene lugar lo organizacional. Esto se hace evidente desde la misma etimología del término Ética, que proviene de dos palabras griegas Ethos y Êthos que se refieren a la costumbre y al carácter, respectivamente. Bajo esta afirmación, llegada del griego antiguo, la Ética, y lo moral, se refieren al habitar del hombre en su mundo (Noguera de Echeverry, 2009). Por ello, el comportamiento Ético hace humano al individuo y lo funde con su medio. La sostenibilidad del medio significa la supervivencia de la especie humana lo que implica volver la mirada al Oykos y el Ethos, es decir al habitar de la casa planetaria (Noguera de Echeverry, 2009). 


\section{Consideraciones finales}

En el camino de su institucionalización, la concepción de la RSO lucha en contra de los reduccionismos economicistas que han llevado a que se le impongan visiones mercantiles. En respuesta, se resalta que la RSO hace parte del constructo ético que relaciona al ser humano con su mundo y por tanto no está circunscrita a un sistema económico particular sino que hace parte de cualquier relación material del ser humano con sus semejantes y su entorno. Más allá de la ganancia pecuniaria, la RSO encuentra su primer fundamento en el comportamiento moral de cada persona. Esto implica el avance más allá de la praxeología organizacional para arribar a las reflexiones ontológicas sobre el orden social.

Si los valores más profundos del Ethos moral y del habitar están presentes en la conducta organizacional y su RSO, la organización no solo apuntará a objetivos productivo-instrumentales sino también a contribuir a la dimensión integral del ser humano.

Esto significa focalizarse en lo humano en sí mismo, la vida y el universo. De ninguna manera esto implica el manejo ineficiente de los recursos organizacionales pero si una desentronización de la eficiencia, llevándola a un lugar subordinado al habitar moral.

El estudio del tema puede proseguir alrededor de tres temas: las instituciones de la RSO; la incorporación de la RSO como elemento obligatorio del entorno, promocionado desde las políticas públicas y la RSO como complemento de los estudios de Gobierno Corporativo y dinámicas de los $\mathrm{Gl}$.

\section{Referencias bibliográficas}

Aguilera-Caracuel, Javier, Guerrero-Villegas, Jaime., \& Morales-Raya, Matilde (2015), Responsabilidad Social y desempeño financiero en multinacionales: influencia de la diversificación internacional. Revista Venezolana de Gerencia, 20(71), 419-439.

Asociación Española de Contabilidad y Administración de Empresas. (2003), Marco conceptual de la responsabilidad social. Comisión de Responsabilidad Social Corporativa. Madrid.

Atkinson, Ron. (2010), What's your responsibility? Quality Progress, 43(4), 21.

Bozeman, Barry. (1987), Todas las organizaciones son públicas: tendiendo un puente entre las teorías corporativas privadas y públicas. México D.F.: Fondo de Cultura Económica.

Carroll, Archie (1979), A three dimensional conceptual model of corporate perfomance. Academy of management review, 4(4), 497-505.

Cegarra Navarro, Juan., \& Rodríguez Carrasco, Jose. (2004), Prácticas de gestión social y componentes de la Responsabilidad social corporativa. Cuadernos de Administración, 17(28), 5370.

Comisión de las comunidades europeas. (2001). Libro verde: Fomentar un marco europeo para la responsabilidad social de las empresas. Bruselas.

Cortina, Adela. (2000), Etica mínima. Introducción a la filosofía práctica. Madrid: Editorial Tecnos S.A.

Drucker, Peter. (1984), The new meaning of Corporate social responsibility. California Management review, 26(2), 53-63.

Dzbankova, Zuzana. (2011), Coporate Social Responsibility: a new way of business 
strategy. Research Journal of Economics, Business and ICT, 3, 26-30.

Elkington, John. (1997), Cannibals with forks. London: Capstone Publishing Limited.

Enderle, George. (2010), Clarifying the terms of business ethics and CSR. Business Ethics Quarterly, 20(4), 730-732.

Freeman, Edward. (1984), Strategic management: a stakeholder approach. Boston: Pitman.

Friedman, Milton. (13 de Septiembre de 1970), The Social Responsibility of Business is to Increase its Profits. The New York Times Magazine, págs. 122126.

Galbreath, Jeremy. (2009), Building corporate social responsibility into strategy. European business review, 21(2), 109-127.

Hatch, M. (1999), Organization Theory. New York: Oxford University press.

Jenkins, Rhys. (2009), What is corporate social responsibility? En J. Peil, \& I. Van Staveren, Handbook of economics and ethics (págs. 69-76). Cheltenham (UK): Edward Elgar Publishing Limited.

Kant, Inmanuel (1778/2012), Fundamentación de la Metafísica de las costumbres. Madrid: Editorial Alianza.

Koslowski, Peter. (2007), Business ethics in globalised financial markets. En K. Homann, P. Koslowski, \& C. Luetge, Globalisation and business ethics (págs. 218-236). Hampshire: Ashgate publishing limited.

Koslowski, Peter. (2008), Some Principles of Ethical Economy. En C. Cowton, \& M. Haase, Trends in business and economic ethics (págs. 31-70). Berlin: Springer.

Markel, Karen \& Barclay, Lizabeth. (2009), Addressing the underemployment of persons with disabilities: recomendations for expanding organizational social responsibility. Employ respons rights journal, 21, 305-318.

Melé, Domenec. (2007), Responsabilidad social de la empresa: una revisión crítica a las principales teorías. Revista vasca de economía Ekonomíaz, 65, 50-67.

Méndez Picazo, Maria. (2005), Etica y responsabilidad social corporativa. Ética y Economía, ICE(823), 141-150.

Noguera de Echeverry, Patricia. (2009), Filosofía ambiental y fenomenología:el paso del sujeto-objeto a la trama de vida en clave de la pregunta por el habitar poético contemporáneo. Acta fenomenológica latinoamericana, III (Actas del IV Coloquio Latinoamericano de Fenomenología), 261-277.

Popa, Oana. (2010), Organizational social responsibility: state of art. Young Economists Journal / Revista Tinerilor Economisti, 8 supplement, 59-68.

Rodríguez, Maria, Pantoja, Martín, \& Cantor, Fernando. (2016), Uso Ético del Poder Gerencial: Propuesta de un Programa para la Formación de Estudiantes de Ingeniería. Formación universitaria, 9(3), 87-98.

Sanabria, José. (2005), Axiología. México D.F.: Porrúa.

Sánchez Vásquez, Adolfo. (1969), Ética. México D.F.: Fondo de cultura económica.

Searle, John. (1997), La construcción de la realidad social. Barcelona: Paidós Iberica.

Simon, Herberth. (1997), Administrative behavior: A study of decision-making processes in administrative organizations. New York: Free Press.

Singer, Marcus. (1989), Value Judgments. En P. Griffiths, Key Themes in Philosophy. Royal institute of philosphy lecture series (págs. 145-172), Cambridge: Cambridge university press. 
Smith, Craig. (2007), Bounded goodness: Marketing implications of Drucker on Corporate responsibility. Centre for Marketing Working paper, 07(104).

Tello Castrillon, Carlos. (2009), Abordaje de conceptos sobre la organizacion. Palmira: Universidad Nacional de Colombia.

Tello Castrillón, Carlos. (2014), Neoinstitucionalismo, Responsabilidad Social Organizacional y Gobernanza. Cuestiones políticas, 30(52), 116-130.

Ungericht, Bernhard \& Hirt, Christian. (2010), CSR as a political arena: the struggle for a European framework. Business and politics, 12(4), 1-22.
Urdaneta, Mary y otros. (2016), Responsabilidad Social en las Universidades del municipio Maracaibo del Estado Zulia. Revista Venezolana de Gerencia, 21(73), 65-85.

World Business Council for Sustainable Development (2002), The business case for sustainable development, WBCSD. Geneva.

Yazdani, Naveed \& Murad, Hasan (2014), Toward an ethical theory of organizing. Journal of Business Ethics, 127(2), 399-417.

Williamson, Oliver (1989), Las instituciones económicas del capitalismo, México D.F.: Fondo de Cultura Económica. 